3 Emmelkamp PM, Kraaen J. Therapist-controlled exposure in vivo versus self-controlled exposure in vivo: a comparison with obsessivecompulsive patients. Behav Res Ther 1977; 15: 491-5.

4 Salkovskis PM. Obsessional-compulsive problems: a cognitivebehavioural analysis. Behav Res Ther 1985; 23: 571-83.

5 Rachman S. A critique of cognitive therapy for anxiety disorders. J Behav Ther Exp Psych 1993; 24: 279-88.

6 Jones MK, Menzies RG. Danger ideation reduction therapy (DIRT): preliminary findings with three obsessive-compulsive washers. Behav Res Ther 1997; 35: 955-60.

7 Jones MK, Menzies RG. Danger ideation reduction therapy (DIRT) for obsessive-compulsive washers. A controlled trial. Behav Res Ther 1998; 36: 959-70.

8 Krochmalik A, Jones MK, Menzies RG. Danger ideation reduction therapy (DIRT) for treatment-resistant compulsive washing. Behav Res Ther 2001; 39: 897-912.

9 van Oppen $\mathrm{P}$, de Haan E, van Balkom AJLM, Spinhoven $\mathrm{P}$, Hoogduin $\mathrm{K}$ van Dyck R. Cognitive therapy and exposure in vivo in the treatment of obsessive-compulsive disorder. Behav Res Ther 1995; 33: 379-90.

10 Emmelkemp PM, Beens H. Cognitive therapy with obsessivecompulsive disorder: a comparative evaluation. Behav Res Ther 1991; 29: 293-300.

11 van Oppen $\mathrm{P}$, van Balkom AJLM, de Haan $\mathrm{E}$, van Dyck R. Cognitive therapy and exposure in vivo alone and in combination with fluvoxamine in obsessive-compulsive disorder: a 5-year follow-up. J Clin Psychiatry 2005; 66: 1415-22.

12 Krone K, Himle J, Nesse R. A standardised behaviour group treatment program for obsessive-compulsive disorder: preliminary outcomes. Behav Res Ther 1991; 23: 627-31.
13 Fals-Stewart W, Marks AP, Shafer J. A comparison of behavioural group therapy and individual behaviour therapy in treating obsessivecompulsive disorder. J Nerv Ment Dis 1993; 181: 189-93.

14 Bouvard M. A standardised cognitive-behavioural group treatment for obsessive-compulsive disorder: preliminary outcomes. Encephale 2002 28: $439-46$.

15 American Psychiatric Association. Diagnostic and Statistical Manual of Mental Disorders (4th edn) (DSM-IV). APA, 2000.

16 Goodman WK, Price LH, Rasmussen SA, Mazure C, Delgado P, Heniger GR, et al. The Yale-Brown Obsessive-Compulsive Scale. 1. Development use and reliability. Arch Gen Psych 1989; 46: 1006-11.

17 Sternberger LG, Burns GL. Maudsley Obsessional-Compulsive Inventory: obsessions and compulsions in a non-clinical sample. Behav Res Ther 1990; 28: 337-40.

18 Marks IM, Matthew AM. Brief standard rating for phobic patients. Behav Res Ther 1979; 17: 263-7.

19 Beck AT, Steer RA, Garbin MG. Psychometric properties of the Beck Depression Inventory: twenty five years of evaluation. Clin Psychol Rev 1988; 8: 77-100

20 Beck AT, Epstein N, Brown G. An inventory for measuring anxiety: psychometric properties. J Consult Clin Psychol 1988; 56: 893-7.

21 de Veaugh-Geiss J, Landau P, Katz R. Preliminary results from a multicentre trial of clomipramine in obsessive-compulsive disorder. Psychopharmac Bull 1989; 25: 36-40.

22 Braga DT, Cordioli AV, Niederauer K, Manfro GG. Cognitive-behavioral group therapy for obsessive-compulsive disorder: a 1 year follow-up. Act Psych Scand 2005; 112: 180-6.

23 Lucey JV, Butcher G, Clare AW, Dinan TG, et al. The clinical characteristics of patients with obsessive compulsive disorder. A descriptive study of an Irish sample. Ir J Psychol Med 1994; 11: 11-4.

\title{
High- $v$. low-dose quetiapine in schizophrenia: meta-analysis
}

\author{
Nitesh Painuly ${ }^{1}$
}

The Psychiatrist (2010), 34, 9-12, doi: 10.1192/pb.bp.108.022277

'Derby City General Hospital

Correspondence to Nitesh Painuly (nitesh.painuly@gmail.com)

\begin{abstract}
Aims and method To study the difference between high- and low-dose quetiapine in acute treatment of schizophrenia. Data available from published double-blind fixeddose trials were combined and analysed.
\end{abstract}

Results There was no statistically significant difference between high- (750$800 \mathrm{mg} /$ day) and low-dose (300-400 mg/day) quetiapine in terms of the response rate, change in positive symptoms score and the discontinuation rates either as a result of lack of response or adverse effects.

Clinical implications Combined evidence from fixed-dose trials does not support the prevalent practice of targeting the higher dose of quetiapine for optimal treatment response in schizophrenia.

Declaration of interest None.
There is uncertainty around the optimal dose of quetiapine in the treatment of schizophrenia. Clinicians in practice prescribe quetiapine at substantially higher dose than that established in clinical trials. ${ }^{1}$ In a recent comprehensive review, ${ }^{2}$ the authors concluded that the balance of evidence does not support the belief that higher dosages are required 
for a full therapeutic response. The present meta-analysis is an attempt to answer this dilemma through combining data available from fixed-dose double-blind controlled studies, which are taken as the most robust evidence in such a doseresponse relationship scenario. ${ }^{2}$ The aim was to look for any definitive and categorical significant differences in efficacy and effectiveness between low- and high-dose quetiapine in the acute treatment of schizophrenia.

\section{Method}

In August 2007, the following databases were searched: PubMed, EMBASE, PsycINFO, AMED (Allied and Complementry Medicine), CINHAL and SSCI (Social SciSearch), with the search terms 'quetiapine AND schizophrenia'. For this meta-analysis, only fixed-dose, doubleblind, randomised controlled trials in the acute treatment of schizophrenia were included. Cross-references of identified articles were checked manually and AstraZeneca in the UK was contacted to access any missing data. The search identified a total of seven fixed-dose published trials. ${ }^{3-9}$ Single fixed-dose trials ${ }^{6,8}$ and the studies with clearly subtherapeutic dosage of quetiapine $(50 \mathrm{mg} /$ day $),{ }^{4,5}$ were excluded from the analysis. A pilot $\operatorname{study}^{7}(n=21)$ that included participants with schizoaffective disorder was also excluded. This ultimately led to the inclusion of only two studies. $^{3,9}$ Quality analysis of the included studies was carried out as per the protocol of the Centre for Reviews and Dissemination (CRD). ${ }^{10}$ Individual and pooled effects of studies were expressed in the form of odds ratio and standardised mean difference with $95 \%$ confidence intervals. A fixed or random effect model was chosen according to the level of heterogeneity within the studies, for which the chi-squared method was used.

\section{Results}

Tables 1 and 2 show the descriptive and pooled results.

\section{Publication bias}

As only two studies were included, funnel chart statistics were not feasible.

\section{Heterogeneity of studies}

No significant heterogeneities were found between the studies with regard to the response rate, discontinuation as a result of lack of response or as a result of adverse effects, but heterogeneity existed for positive symptoms scores $(P<0.05)$.

\section{Pooled results}

There was no statistically significant difference between high- and low-dose quetiapine in terms of the response rate and the discontinuation due to lack of response or due to adverse effects. An alternate analysis was done for the response rate after excluding those individuals who had dropped out from the total number of participants. Again, the odds ratio in favour of high-dose quetiapine was not statistically significant (OR $=1.40,95 \%$ CI $0.80-2.44)$. There was no statistically significant difference between high- and
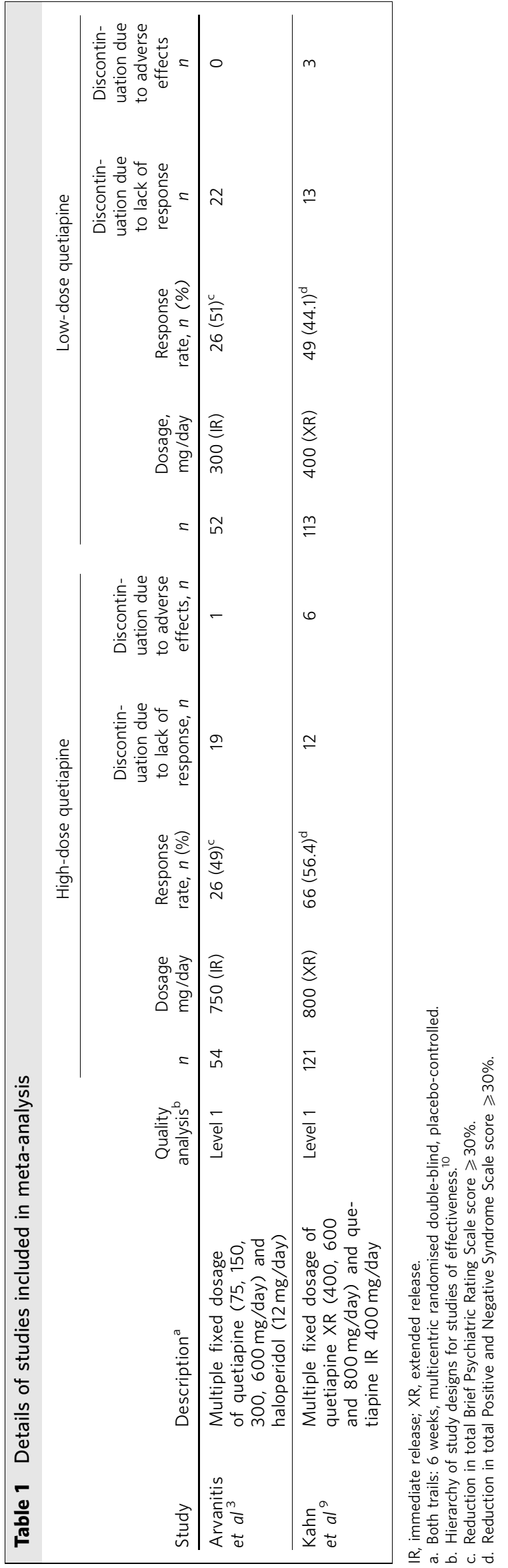


\begin{tabular}{|c|c|c|c|}
\hline Results & Response rate & $\begin{array}{l}\text { Discontinuation due } \\
\text { to lack of response }\end{array}$ & $\begin{array}{l}\text { Discontinuation due } \\
\text { to adverse effects }\end{array}$ \\
\hline \multicolumn{4}{|l|}{ Odds ratio $(95 \% \mathrm{Cl})$} \\
\hline Arvanitis et $a l^{3}$ & $0.93(0.43-1.99)$ & $0.74(0.34-1.62)$ & $7.12(0.14-359.12)$ \\
\hline Kahn et $a^{9}$ & $1.63(0.97-2.74)$ & $0.85(0.37-1.94)$ & $0.47(0.12-1.77)$ \\
\hline Test of heterogeneity, ${ }^{a} \mathrm{Q}(P)$ & $1.44(0.22)$ & $0.05(0.82)$ & $1.66(0.19)$ \\
\hline Pooled effect $(95 \% \mathrm{Cl})^{b}$ & $1.36(0.88-2.10)$ & $0.78(0.44-1.39)$ & $0.64(0.19-2.17)$ \\
\hline
\end{tabular}

a. Chi-squared distribution. d.f $=1$ for all. No heterogeneity present for all.

b. Fixed effect model.

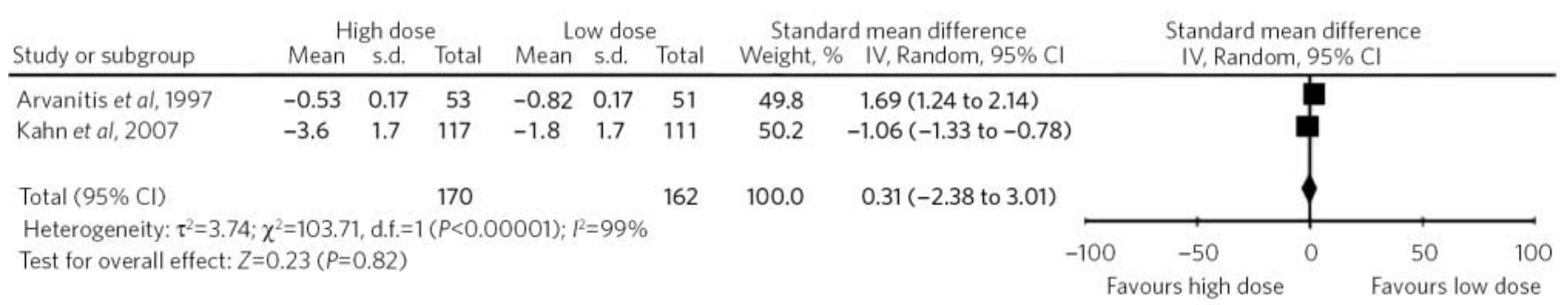

Fig 1 Change in positive symptoms score (forest plot).

IV, inverse variance.

low-dose quetiapine for improvement in positive symptoms score (Fig. 1).

\section{Discussion}

Findings of this meta-analysis are in a line with those of Sparshatt et $a l^{2}$ and Buckley. ${ }^{11}$ Buckley ${ }^{11}$ undertook a combined analysis of three randomised, placebo-controlled trials and divided participants into two groups - those receiving quetiapine $<400 \mathrm{mg} /$ day and those receiving $>400 \mathrm{mg} /$ day. Although differences in the Brief Psychiatric Rating Scale positive symptom cluster scores was numerically greater in the higher dosage group it was not statistically significant. The possibility of this difference becoming significant is raised if the study by Kahn et $a l^{9}$ (which shows a statistically significant relationship between increasing dosage and therapeutic effect) is included. ${ }^{2}$ Present meta-analysis shows that this is not the case as standardised mean difference on positive symptoms score is not significantly different in both groups (Fig. 1). It is possible that high-dose quetiapine might prove to be superior in the long term as these trials were only 6 weeks long. Also, certain participants with treatment resistance or comorbid substance misuse, who are not represented in these trials, might respond only to the highdose quetiapine. From the effectiveness prospective, highand low-dose quetiapine do not show very different discontinuation rates, but the small number of participants included in the analysis and the very wide range of the confidence interval raises the question of the validity of these results.

The major limitation of this meta-analysis is that only two studies ${ }^{3,9}$ could be included in the meta-analysis, which not only adds a significant publication bias but also limits the power of the study to give any definitive answer. Regarding heterogeneity, both studies used different preparations of quetiapine and different scales for measuring outcome. Kahn et $a l^{9}$ excluded people with treatment resistance, substance misuse and a hospital stay $>1$ month; whereas in the study by Arvanitis et $a l^{3}$ all the participants were in-patients. Also, it should be remembered that limitations inherent to individual studies are carried over in meta-analyses; and meta-analyses tend to neglect the specifications of the individual studies.

In conclusion, this meta-analysis does not prove the therapeutic superiority of high-dose quetiapine in acute treatment of schizophrenia; both in terms of efficacy and effectiveness. From a clinical practice point of view, in general, $300-400 \mathrm{mg} /$ day seems to be the optimal dose of quetiapine and the common practice of targeting quetiapine dosage to $600 \mathrm{mg} /$ day or above is not supported by the evidence from fixed-dose trials.

\section{Acknowledgements}

Sincere thanks to Dr Subodh Dave (Consultant Psychiatrist and Clinical Teaching Fellow, Derby City General Hospital) for his valuable suggestions in revision of the manuscript.

\section{About the author}

Nitesh Painuly is a Consultant Psychiatrist at Derby City General Hospital, Derbyshire Mental Health Services NHS Trust.

\section{References}

1 Citrome L, Jaffe A, Levine J, Lindenmayer JP. Dosing of quetiapine in schizophrenia: how clinical practice differs from registration studies. J Clin Psychiatry 2005; 66: 1512-6. 
2 Sparshatt A, Jones S, Taylor D. Quetiapine: dose-response relationship in schizophrenia. CNS Drugs 2008; 22: 49-68.

3 Arvanitis LA, Miller BG. Multiple fixed dose of 'Seroquel' (quetiapine) in patients with acute exacerbation of schizophrenia: a comparison with haloperidol and placebo. Biol Psychiatry 1997; 42: 233-46.

4 King DJ, Link CGG, Kowalcyk B. A comparison of bd and tid dose regimens of quetiapine (Seroquel) in the treatment of schizophrenia. Psychopharmacology 1998; 137: 139-46.

5 Barzega G, Bogetto F, Maina G, Ravizza L. Quetiapine in schizophrenic patients: a high- and low-dose double-blind comparison. Eur J Psychiatry 2000; 14: 221-32.

6 Emsley RA, Raniwalla J, Bailey PJ, Jones AM. A comparison of the effects of quetiapine ('Seroquel') and haloperidol in schizophrenic patients with a history of and a demonstrated, partial response to conventional antipsychotic treatment. Int Clin Psychopharmacol 2000; 15: $121-31$

7 Roy Chengappa KN, Parepally H, Brar JS, Mullen J, Shilling A, Goldstein JM. A random-assignment, double-blind, clinical trial of once- vs twicedaily administration of quetiapine fumarate in patients with schizophrenia or schizoaffective disorder: a pilot study. Can J Psychiatry 2003; 48: 187-94.

8 Conley RR, Kelly DL, Nelson MW, Richardson CM, Feldman S, Benham R, et al. Risperidone, quetiapine, and fluphenazine in the treatment of patients with therapy-refractory schizophrenia. Clin Neuropharmacol 2005; 28: 163-8.

9 Kahn RS, Schulz C, Palazov VD, Reyes EB, Brecher M, Svensson O, et al. Efficacy and tolerability of once-daily extended release quetiapine fumarate in acute schizophrenia: a randomized, double blind, placebocontrolled study. J Clin Psychiatry 2007; 68: 832-42.

10 Centre for Reviews and Dissemination. Undertaking Systematic Reviews of Research on Effectiveness: CRD's Guidance for Those Carrying Out or Commissioning Reviews. Centre for Reviews and Dissemination (CRD), Report 4 (2nd edn). CRD, 2001 (http://www.york.ac.uk/inst/crd/ report4.htm).

11 Buckley PF. Efficacy of quetiapine for the treatment of schizophrenia: a combined analysis of three placebo-controlled trials. Curr Med Res Opin 2004; 20: 1357-63.

\title{
Olive Tree community treatment centre for individuals with personality disorder: naturalistic service evaluation
}

\author{
Johannes L. Pretorius, ${ }^{1}$ Alberto Albeniz, ${ }^{2}$ Matthew Broome ${ }^{3}$
}

The Psychiatrist (2010), 34, 12-20, doi: 10.1192/pb.bp.108.023192

${ }^{1}$ Olive Tree Personality Disorders Unit, Coventry; ${ }^{2}$ Walsgrave Hospital,

Coventry; ${ }^{3}$ University of Warwick

Correspondence to

Johannes Pretorius

(wikus.pretorius@covwarkpt.nhs.uk)
Aims and method Community treatment for individuals with personality disorder is a fast developing field. We report here on the effectiveness of one such approach. We examine the referral pathway of all clients between January 2005 and April 2008, including the mean days spent in our unit, the days spent in a psychiatric hospital before and after admission to our unit, and the results of changes in the rating scales we routinely use.

Results Drop-out rates and the mean duration of therapy were acceptable. There has been a clear reduction of in-patient bed use and a small but significant improvement of most psychometric test results.

Clinical implications This study provides further evidence for the effectiveness of community treatment for individuals with personality disorder.

Declaration of interest None.
The Department of Health 2003 policy implementation guideline Personality Disorder: No Longer a Diagnosis of Exclusion ${ }^{1}$ set out to the UK's National Health Service (NHS) trusts the government's intentions for the delivery of personality disorder services within general mental health and forensic settings. In this document, the government built on standards four and five in the National Service Framework for Mental Health ${ }^{2}$ and set out specific guidance on the development of services for people with personality disorder. It made explicit that all trusts delivering general adult mental health services need to consider how to meet the needs of individuals with a personality disorder who experience significant distress or difficulty as a result of their disorder. Later in 2003, a further National Institute for Mental Health in England publication ${ }^{3}$ indicated that new funds would be made available to help stimulate the development of improved and new services to support users with personality disorders. The Olive Tree community treatment centre for individuals with personality disorder, created by the Coventry Primary Care Trust, became one of the pilots of this government initiative. ${ }^{4,5}$ At a time of change in the field of personality disorders, possible changes in classification and 